\title{
Depression Waves Generated by Large Ships in the Venice Lagoon
}

\author{
Kevin E. Parnell ${ }^{\dagger *}$, Luca Zaggia ${ }^{\ddagger}$, Tarmo Soomere ${ }^{\S}$, Giuliano Lorenzetti ${ }^{\ddagger}$, and Gian Marco Scarpa ${ }^{\dagger \dagger}$ \\ ${ }^{\dagger}$ College of Marine and Environmental Sciences \\ James Cook University \\ Townsville, Australia \\ ¥Institute of Marine Sciences \\ National Research Council \\ Venice, Italy \\ ${ }^{\S}$ Institute of Cybernetics \\ Tallinn University of Technology \\ Tallinn, Estonia \\ thenvironmental Sciences, Informatics and Statistics \\ Università Ca' Foscari \\ Venice, Italy
}

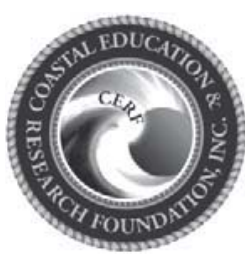

www.cerf-jcr.org



www.JCRonline.org

\begin{abstract}
Parnell, K.E.; Zaggia, L.; Soomere, T.; Lorenzetti, G., and Scarpa, G-M. 2016. Depression waves generated by large ships in the Venice Lagoon. In: Vila-Concejo, A.; Bruce, E.; Kennedy, D.M., and McCarroll, R.J. (eds.), Proceedings of the 14th International Coastal Symposium (Sydney, Australia). Journal of Coastal Research, Special Issue, No. 75, pp. 907-911. Coconut Creek (Florida), ISSN 0749-0208.

At present cruise ships use the Lido and Giudecca channels to berth at the Port of Venice, and cargo vessels use the Malamocco-Marghera channel to berth at the Marghera industrial area. Following a government decree to restrict large ship access to the Port of Venice through the Lido and Giudecca channels, the Port authority has been investigating the construction of a new channel between Marghera and the cruise terminal, to re-route all large vessels through the Malamocco lagoon entrance. Ships in the Venice Lagoon travel at low speeds with associated low depth-based Froude numbers $(<0.5)$, and classical Kelvin wave effects are minimal. However, under certain channel geometries, depression waves (also known as Bernoulli wake) can be substantial with significant far-field effects. In the Malamocco-Marghera Channel, depression waves up to $2.5 \mathrm{~m}$, with high $(\sim 1.5 \mathrm{~m} / \mathrm{s})$ near bed water speeds, transform into asymmetric Riemann waves, able to propagate large distances from the navigation channel into the shallow lagoon. By contrast, depression waves associated with large ships in the Lido and Giudecca channels are much smaller $(\sim 0.3-0.4 \mathrm{~m})$. Rerouting large cruise ships entering the Port of Venice through the MalamoccoMarghera channel and a newly constructed channel will have adverse effects on the Venice lagoon with increased water velocities and sediment resuspension associated with the nonlinear Riemann waves. It is therefore essential that the potential effects be thoroughly evaluated using an appropriate methodology before the development of a new lagoon channel.
\end{abstract}

ADDITIONAL INDEX WORDS: Bernoulli wake, vessel wakes, Riemann waves, nonlinear waves.

\section{INTRODUCTION}

The classic theory of ship-generated wakes focuses on the properties of surface undulations created by moving vessels (Newman, 1977). In the open deep ocean the influence of wake waves on water mass dynamics is negligible. Wake waves and their specific nonlinear components (such as precursor solitons), particularly for vessels travelling at high speed, play a much larger role in shallower areas (Didenkulova et al., 2009; Erm and Soomere, 2006; Parnell and Kofoed-Hansen, 2001; Parnell et al., 2007; Soomere et al., 2011).

The governing parameter for wave generation is the depthbased Froude number $F_{d}$, the ratio of the vessel speed $V$ and the maximum wave celerity for the depth $d$. If this parameter is below 0.6-0.7, the wave system resembles the Kelvin wake, while at values $F_{d}$ in the high-speed subcritical range $0.7-1$, various nonlinear phenomena become evident (Soomere, 2007). The structure of wave wake at supercritical speeds $\left(F_{d}>1\right)$ is fundamentally different and resembles a Mach-type

DOI: 10.2112/SI75-182.1 received 15 October 2015; accepted in revision 15 January 2016.

*Corresponding author: kevin.parnell@jcu.edu.au

${ }^{\circ}$ Coastal Education and Research Foundation, Inc. 2016 system (Pethiyagoda et al., 2014; Rabaud and Moisy, 2013).

While most components of wake waves are either almost linear or can be described by weakly nonlinear models, recent research has highlighted the effects of a depression wave, a strongly nonlinear ship-generated disturbance. Often called a Bernoulli wake, it is an intrinsic part of moving in shallow or narrow waterways. It becomes evident as 'squat' (Naghdi and Rubin, 1984) where lower pressure around the ship causes it to be closer to the seabed than in deep water. It is commonly thought that the resulting depression is located only in the immediate vicinity of the ship.

In certain geometries of the fairway, waves of elevation are almost negligible and almost all energy is concentrated in the depression wave. Such a situation occurs in the narrow and shallow navigation channels in the Venice Lagoon (Figure 1). Even though all large ships in the Venice Lagoon travel at low speeds with associated low depth-based Froude numbers $(<0.5)$ and classical Kelvin wave effects are minimal, vesselgenerated single depressions in an $\sim 12 \mathrm{~m}$ deep waterway can be as much as $2.5 \mathrm{~m}$ (Parnell et al., 2015). These entities are highly nonlinear and they propagate over the shallow-water areas as long-living solitary depression waves at least $\sim 1 \mathrm{~km}$ into the lagoon (Rodin et al., 2015). In the shallow and muddy 
lagoon they create high water velocities and intense resuspension (Rapaglia et al., 2011), possibly leading to serious environmental consequences for large parts of the Venice Lagoon (Gelinas et al., 2013; Rapaglia et al., 2015).

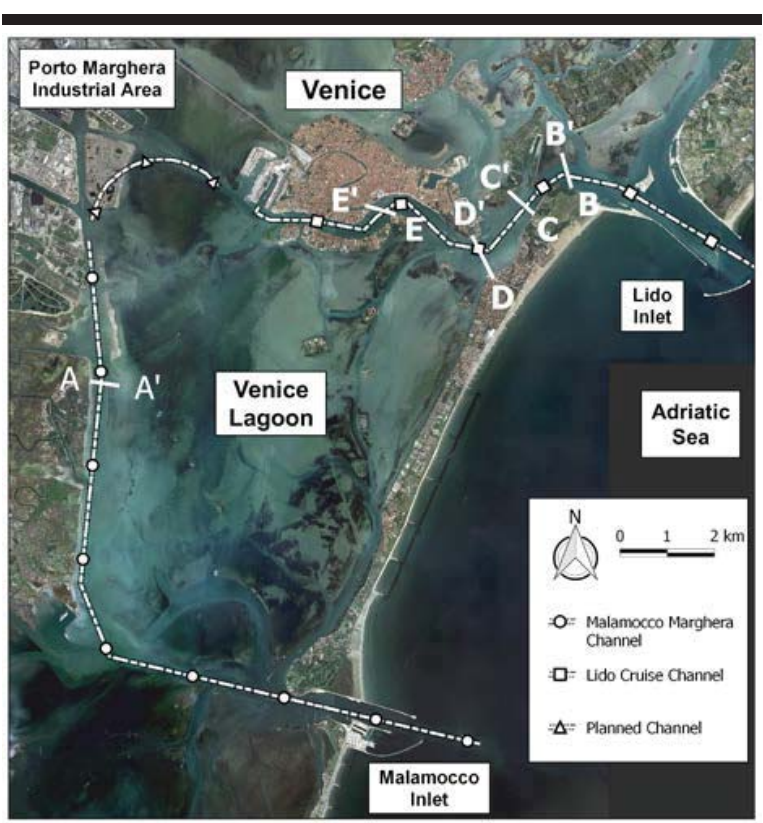

Figure 1. The Venice lagoon, showing the Malamocco-Marghera channel, used by cargo ships, the Lido channel used by cruise ships and the most recently suggested location of a channel that may be constructed so that cruise ships can reach the passenger terminal through the Malamocco entrance. The location of cross sections on which data were collected are also indicated. The cross section areas (at local datum level where MSL $=-0.26 \mathrm{~m}$ ) are: A $1910 \mathrm{~m}^{2}$; B $5053 \mathrm{~m}^{2}$; C $4301 \mathrm{~m}^{2}$; D $3546 \mathrm{~m}^{2}$; E $4080 \mathrm{~m}^{2}$.

The largest depressions rapidly lose a large part of their height when travelling over the first $100-200 \mathrm{~m}$ in the lagoon and the amplitude of the depression wave in the shallow lagoon only weakly depends on the initial amplitude of the wave (Rodin et al., 2015). Therefore, even relatively modest depression waves, generated in narrow channels constructed in a shallow lagoon may penetrate to substantial distances into the lagoon provided their amplitude is large enough to ensure a strongly nonlinear regime of propagation.

At present, cruise ships use the Lido entrance to the Venice Lagoon and the Lido and Giudecca channels to berth at the Venice cruise ship terminal, and cargo vessels use the Malamocco entrance and the Malamocco-Marghera channel to berth at the Marghera industrial area (Figure 1). Pressure to restrict large ship access to the Port of Venice through the Lido and Giudecca channels increased after the 'Costa Concordia' disaster in the Tuscan archipelago, and the level of protest increased. Stated reasons to exclude large ships from the Lido and Giudecca channels include aesthetics, the risk of accidents, safety, and wake-wave effects, particularly on structures. The national government notified a future ban (by decree) that forced the Port of Venice to investigate the construction of a new channel between the MalamoccoMarghera channel and the cruise ship terminal, to enable the re-routing of all vessels through the Malamocco entrance.

In this paper we discuss the properties and propagation of ship-induced depression waves generated by ships in a section of the Malamocco-Marghera industrial channel. We compare these depression waves with those generated by cruise ships in the Lido and Giudecca channels, and consider the implications of re-routing cruise ships to the MalamoccoMarghera channel and a potential newly constructed channel providing access to the Venice cruise terminal.

\section{METHODS}

The Venice Lagoon has a surface area of $550 \mathrm{~km}^{2}$ and average depth of $0.8 \mathrm{~m}$ (Brambati et al., 2003). Water circulation is mainly controlled by tides with tidal range between 0.3 and $1.1 \mathrm{~m}$. The lagoon has three inlets with depths from about $10 \mathrm{~m}$ to $>17 \mathrm{~m}$ (the Malamocco inlet).

Ship wake measurements were performed in the Malamocco-Marghera navigation channel, south of the industrial area of Marghera (Figure 2). Self-recording pressure sensors housed in different instruments were deployed in 8 positions across a section (Parnell et al., 2015), from the channel margins, extending to the shoreline on the Eastern side (' $\mathrm{B}$ ' locations in Figure 2) and to a breakwater protection on the Western side ('W' locations in Figure 2). At some locations InterOcean S4 current meters were deployed with directional currents being recorded. We underestimated the water speeds that the current meters would experience, and the current meters overturned due to insufficient anchor weight and drag on surface buoys. Consequently, on a number of occasions during early deployments, current data were lost. Therefore, where noted, the reported speeds are the highest recorded before the current meter tilted and are therefore likely to be less than the true maximums. Data were recorded at either 2 or $5 \mathrm{~Hz}$ acquisition frequency over four sampling periods of between 2 to 6 days in March and April 2014. Approximately 90 cargo vessel passages were recorded. Ships travelled at speeds of between 6 and 11.5 knots, with blocking ratios $C^{*}$ (width $W$ x draught $D$ of the vessel / cross-sectional area of the channel), between 0.02 and 0.14 , and with depth Froude numbers $\left(F_{d}\right)$ between 0.3 and 0.55 (clearly in the sub-critical range). Two examples are shown (Table 1; Figure $3)$.

Table 1. Vessel details for the Abu Dhabi Star and Domenico Ievoli (Malamocco-Marghera channel) and MSC Preziosa and Costa Fascinosa (Lido and Giudecca channels)

\begin{tabular}{|c|c|c|c|c|c|c|}
\hline Ship & $\begin{array}{l}\text { Length } \\
\text { (m) }\end{array}$ & $\begin{array}{c}W \\
(m)\end{array}$ & $\begin{array}{c}D \\
(m)\end{array}$ & $\begin{array}{c}V \\
(\mathrm{kn})\end{array}$ & $C^{*}$ & $F_{d}$ \\
\hline $\begin{array}{l}\text { Abu Dhabi } \\
\text { Star }\end{array}$ & 183 & 32 & 7.8 & 7.7 & 0.14 & 0.37 \\
\hline $\begin{array}{l}\text { Domenico } \\
\text { Ievoli }\end{array}$ & 146 & 20 & 6.6 & 10.4 & 0.07 & 0.50 \\
\hline $\begin{array}{c}\text { MSC } \\
\text { Preziosa }\end{array}$ & 333 & 38 & 8.6 & $\begin{array}{c}5.2 \\
\text { to } \\
7.5\end{array}$ & $\begin{array}{c}0.06 \\
\text { to } \\
0.09\end{array}$ & $\begin{array}{c}0.23 \\
\text { to } \\
0.35\end{array}$ \\
\hline Costa & 289 & 36 & 8.3 & 5.7 & 0.05 & 0.23 \\
\hline
\end{tabular}






Figure 2. Study site in the Marghera-Malamocco channel.

Wake measurements of cruise ships MSC Preziosa on 5 April 2014 and Costa Fascinosa on 7 April 2014, passing through the Lido and Giudecca channels were obtained during a sampling period from 4 to 8 April 2014 (Table 1). Measurements were taken near the channel edge. Eight instruments were deployed, all measuring pressure with four InterOcean S4 current meters also measuring directional currents. Typically, cruise ships enter Venice in the early morning and depart in the late afternoon or early evening.

\section{RESULTS}

Two examples of depression waves from cargo vessels on a cross section in the Marghera-Malamocco channel are shown in Figure 3, and are presented as actual water depths at the time of the ships passage. Because of the low speed (7.7 and 10.4 knots, with corresponding $F_{d}$ of 0.37 and 0.50 ) signvariable wave groups or solitary waves of elevation were not evident. The most noticeable feature was a deep depression typically lasting $\sim 80 \mathrm{~s}$. Of the $\sim 90$ records, Abu Dhabi Star, an unremarkable ship in terms of its size and speed, produced the largest depression wave of $2.5 \mathrm{~m}$ from still water level. A common feature of the depressions was the difference in size at the opposite sides of the channel. On the lagoon side the depression wave generated by the Abu Dhabi Star was only $1.6 \mathrm{~m}$. The depression wave of the Domenico Ievoli, travelling in the opposite direction, was larger on the lagoon side. The depressions were almost perfectly symmetric at the channel margins, but became asymmetric with the front slope becoming less steep and the rear slope becoming steeper, as the waves crossed the adjacent shoals. Virtually all records showed the development of a step on the rear slope of the depression wave. Parnell et al. (2015) show that these waves are described reasonably well as long-living strongly nonlinear solitary Riemann depression waves. At those sites where water speeds were also recorded (B1, B2, W1 and W2), even small depression waves generated high near bed speeds (greater than $0.65 \mathrm{~m} / \mathrm{s}$ in the examples shown). In the case of
Abu Dhabi Star, near bed speeds of at least $1.89 \mathrm{~m} / \mathrm{s}$ were recorded before the current meter was overturned.

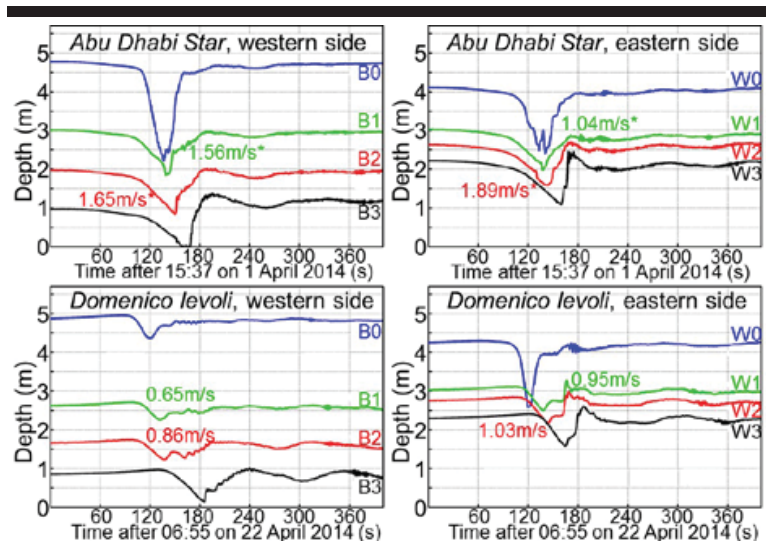

Figure 3. Depression waves in the Marghera-Malamocco channel. Water speeds are the maximum recorded $\sim 20 \mathrm{~cm}$ above the seabed. Speeds labelled $*$ are the maximum recorded before the instrument was overturned. Actual maximum speeds are likely to be higher.

Waves generated by MSC Preziosa in the Lido and Giudecca channels are presented in Figure 4. Depression waves generated by Costa Fascinosa, measured on a different day, were almost identical in shape but smaller in magnitude than those for MSC Preziosa. Data are not presented from sites B, C', D' and a site $250 \mathrm{~m}$ west of B', but they typically showed waves that were smaller than or similar to those illustrated. At site D', no depression waves were recorded.

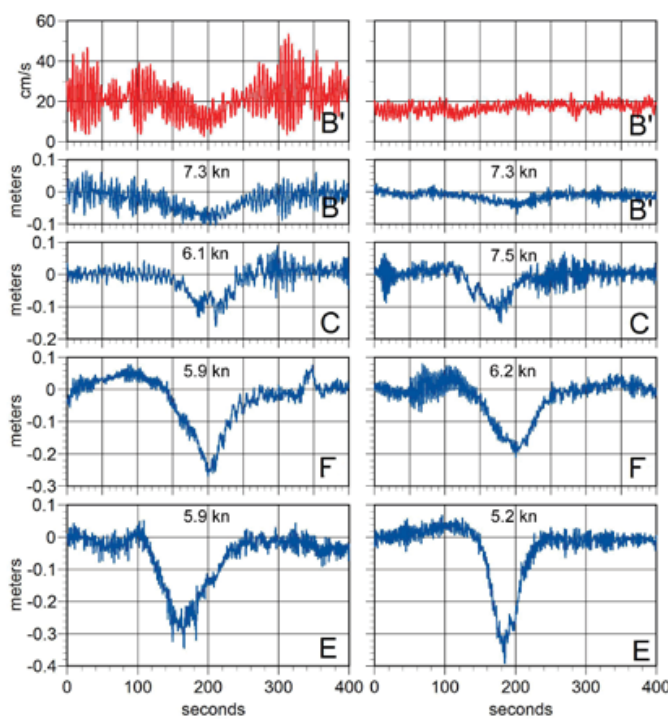

Figure 4. Depression waves generated by MSC Preziosa at sites in the Giudecca and Lido channels (see Figure 1), incoming to Venice on the left and outgoing on the right. Zero is the average water surface in the first 30 seconds of the record. The top graphs (red) show water velocities approximately $1 \mathrm{~m}$ from the bed at site B'. The speed of the 
ship passing the site is shown in knots.

In the Lido and Giudecca channels, the largest measured depression wave was $0.4 \mathrm{~m}$ from still water level at site E., with the next largest wave $(0.26 \mathrm{~m}$, although preceded by a $0.04 \mathrm{~m}$ increase in water level) at site F. Smaller depression waves were observed at other measurement sites further east. This is surprising as the ships were at their slowest speeds at sites $\mathrm{E}$ and $\mathrm{F}$, and the cross section area of the channel (and therefore the blocking ratios) were not significantly different to cross sections $\mathrm{C}$ and $\mathrm{D}$, however, the ship tracks took them quite close to these two gauge sites. The depression waves (measured close to the channel edge) are all nearly symmetric.

The water level variations caused by the combined effects of wind generated waves and the multitude of smaller vessels are also clearly seen as background noise on the main trend. No sign-variable waves caused by the cruise ships are apparent in the record, although as evidenced by the water level rise in a few records, precursor solitons may occur, the magnitude of which is only in the order of a few centimeters.

The graphs in red in Figure 4 show the near bed water speeds associated with the passage of MSC Preziosa. Tidal currents at this site averaged $23 \mathrm{~cm} / \mathrm{s}$ during the incoming passage. As MSC Preziosa had been announced to be the largest vessel ever to enter Venice through the Lido entrance, it was accompanied by a number of small spectator boats. The small boat wakes (and possibly some wind driven waves) can be seen. The effect of the depression wake on water speeds was to reduce the average (tidal) current and change the water movement direction. This was typical of all records for which we had water velocity data.

\section{DISCUSSION}

The depression waves generated by large cruise ships in the Lido and Giudecca channels are significantly smaller than those generated by cargo vessels in the Marghera-Malamocco channel. The precise combination of factors to explain this are not fully understood. Blocking ratios for cruise ships in the Lido and Giudecca channels were approximately the same as for the smaller cargo vessels in the Marghera-Malamocco channel (e.g. Domenico Ioveli), but significantly less than the larger cargo vessels (e.g. Abu Dhabi Star). The impact of channel geometry on the depression wave size has not been established. The cruise ships were travelling slightly slower than was typical for the cargo ships (with correspondingly smaller $F_{d}$ ), which may have been influential. The proximity of the ship to the measurement site is probably an important factor, to the extent that significantly different amplitudes of the depression are observed on different sides of the channel, although this is not tested in this study.

The potential impact of depression waves propagating as strongly nonlinear Riemann waves across wide and shallow shoals has been demonstrated by Parnell et al. (2015) and Rodin et al. (2015). Provided that their amplitude is large enough to ensure a strongly nonlinear regime of propagation, waves generated in a narrow channel constructed in a shallow lagoon may penetrate to substantial distances. Numerical simulations have shown that once established, the initial size of the depression wave is not significant, as the height of the wave reduces to a common level after some propagation time, meaning that depression waves of even a modest size may produce the theoretically maximum amplitude in the lagoon, potentially $>0.3 \mathrm{~m}$ (Rodin et al., 2015). The propagating wave becomes highly asymmetric, with a gently sloping front and a very steep rear, even at a distance $>1 \mathrm{~km}$ from the navigation channel. Rapaglia et al. (2015) demonstrate the significant effect of such waves on water speeds and sediment resuspension and transport in the lagoon, including the resuspension of contaminated sediments, and safety issues, particularly associated with the steep rear slope of the propagating wave (Rodin et al., 2015).

The conditions described above, a channel with extensive adjacent shallow shoals, occurs over the entire length of the Marghera-Malamocco channel and in the eastern parts of the Lido channel. Whereas depression waves of sufficient amplitude to form nonlinear Riemann waves in the shallows always or almost always occur in the Marghera-Malamocco channel, our data suggests that waves of sufficient size are not generated by the cruise ships in the Lido channel. Once in the Giudecca channel, where larger depression waves apparently form, the morphological conditions for the development of nonlinear Riemann waves do not exist. The direct wake effects of cruise ships in the Lido and Giudecca channels therefore appear to be small, although increased velocities in adjacent channels may still result (Costa and Zuliani, 2004).

There is currently a directive to reroute cruise ships entering the cruise ship terminal in Venice through the Marghera-Malamocco channel and a new channel to be constructed. While there may be many reasons why such a move is the right thing to do (aesthetics, risks of spills or accidents, safety, conflict with other users), most wake related issues are almost certainly much less significant. However, an increase in the number of large ships with blocking ratios larger than those of cargo ships (calculated at cross section A of 0.18 for MSC Preziosa and 0.17 for Costa Fascinosa, compared to 0.14 for Abu Dhabi Star) in the MargheraMalamocco channel and in a newly constructed channel could cause a significantly increased impact on the lagoon ecosystems in an area which has been already heavily impacted (Sarretta et al., 2010) and on the safety and convenience of other users of the lagoon.

Shipping channels with extensive adjacent shallow water areas are common on the approaches to ports. The far-field impact of depression waves generated in such channels has been demonstrated (Rapaglia et al., 2011, 2014; Parnell et al., 2015; Rodin et al., 2015) and their further propagation has been acceptably replicated in the strongly nonlinear framework of Riemann waves (Parnell et al., 2015; Rodin et al., 2015). However, the physics of their generation is yet to be clarified. While the wakes generated by ships is now generally well understood and several features of the wake signature for particular ships are remarkably stable (Torsvik et al., 2015), it may be necessary to test ships sailing in navigation channels surrounded by wide and shallow banks with respect to their ability to excite potentially dangerous depression waves.

\section{CONCLUSIONS}


Although depression waves (otherwise called Bernoulli wakes), have been well known for some time, their structure and impacts after propagation over wide and shallow banks has only recently been described in the context of nonlinear Riemann wave theory, using the case of the MargheraMalamocco channel in the Venice lagoon. We demonstrate that these wakes, generated by cargo vessels, can have significant amplitude. Even larger cruise ships transiting the Lido and Giudecca channels generate much smaller depression waves in the outer parts of the route, potentially too small to establish nonlinear effects, and on the inner section of the route, where waves of up to $0.4 \mathrm{~m}$ were recorded, the lack of adjacent shallow areas means that the effects are likely to be minimal.

The proposal to reroute ships from the Lido and Giudecca channels through the Marghera-Malamocco channel and a newly constructed channel will lead to larger and more ships transiting this route, and may have significant further impact on lagoon morphodynamics with substantial effects on ecosystem services, and on the safety and convenience of other lagoon users. It is therefore essential that the effects of this change be investigated using an appropriate methodology before such a project is implemented.

\section{ACKNOWLEDGMENTS}

This work was supported by the institutional financing by the Estonian Ministry of Education and Research (grant IUT33-3), and the Estonian Science Foundation (from 2011 Estonian Research Council) grant 9125. The field studies were undertaken during Parnell's visit to CNR-ISMAR, Venice, Italy, and were funded by the project Ritmare (SP3WP3-A1).

\section{LITERATURE CITED}

Brambati, A.; Carbognin, L.; Quaia, T.; Teatini, P., and Tosi, L., 2003. The Lagoon of Venice: geological setting, evolution and land subsidence. Episodes, 26(3), 264-265.

Costa, F. and Zuliani, A., 2004. Analisi degli effetti idrodinamici indotti nei rii in corrispondenza del passaggio delle grandi navi da crociera: Relazione di sintesi, CNRISMAR, Venezia, 17p. (in Italian)

Didenkulova, I.; Parnell, K.E.; Soomere, T.; Pelinovsky, E., and Kurennoy, D., 2009. Shoaling and runup of long waves induced by high-speed ferries in Tallinn Bay. Journal of Coastal Research, Special Issue No. 56, pp. 491-495.

Erm, A. and Soomere, T., 2006. The impact of fast ferry traffic on underwater optics and sediment resuspension. Oceanologia, 48(S), pp. 283-301.

Gelinas, M.; Bokuniewicz, H.; Rapaglia, J., and Lwiza, K.M.M., 2013. Sediment resuspension by ship wakes in the Venice Lagoon. Journal of Coastal Research, 29, 8-17.

Kelpšaite, L.; Parnell, K.E., and Soomere, T., 2009. Energy pollution: the relative influence of wind-wave and vesselwake energy in Tallinn Bay, the Baltic Sea. Journal of Coastal Research, SI 56, 812-816.

Naghdi, P. and Rubin, M., 1984. On the squat of a ship. Journal of. Ship Research. 28, 107-117.
Newman, J.N., 1977. Marine hydrodynamics. Cambridge, Massachusetts: MIT Press, 402p.

Parnell, K.E. and Kofoed-Hansen, H., 2001. Wakes from large high-speed ferries in confined coastal waters: Management approaches with examples from New Zealand and Denmark. Coastal Management, 29 (3), 217-237.

Parnell, K.E.; McDonald, S.C., and Burke, A.E., 2007. Shoreline effects of vessel wakes, Marlborough Sounds, New Zealand. Journal of Coastal Research, SI 50, 502506.

Parnell, K.E.; $\quad$ Soomere, T.; $\quad$ Zaggia, L.; $\quad$ Rodin, A.; Lorenzetti, G.; Rapaglia, J., and Scarpa, G-M., 2015. Shipinduced solitary Riemann waves of depression in Venice Lagoon. Physics Letters A, 379(6), 555-559.

Pethiyagoda, R.; McCue, S.W., and Moroney, T.J., 2014. What is the angle of a nonlinear Kelvin ship wave pattern? Journal of. Fluid Mechanics. 758, 468-485.

Rabaud, M. and Moisy, F., 2013. Ship wakes: Kelvin or Mach angle? Physical. Review. Letters. 110 (21), No. 214503.

Rapaglia, J.; Zaggia, L.; Ricklefs, K.; Gelinas, M., and Bokuniewicz, H., 2011. Characteristics of ships' depression waves and associated sediment resuspension in Venice Lagoon, Italy. Journal of Marine Systems, 85(1-2), 45-56.

Rapaglia, J.; Zaggia, L.; Parnell, K.E.; Lorenzetti, G., and Vafeidis, A.T., 2015. Ship-wake induced sediment remobilization: Effects and proposed management strategies for the Venice Lagoon. Ocean \& Coastal Management 110, 1-11.

Rodin, A.; Soomere, T.; Parnell, K.E., and Zaggia, L., 2015. Numerical simulation of the propagation of ship-induced Riemann waves of depression into Venice Lagoon. Proceedings of the Estonian Academy of Sciences, 64 (1), 22-35.

Saretta, A.; Pillon, S.; Molinaroli, E.; Guerzoni, S., and Fontolan, G., 2010. Sediment budget in the Lagoon of Venice, Italy. Continental Shelf Research,. 30, 934-949.

Soomere, T., 2007. Nonlinear components of ship wake waves, Applied Mechanics Reviews, 60 (3), 120-138.

Soomere, T.; Parnell, K.E., and Didenkulova, I., 2011. Water transport in wake waves from high-speed vessels, Journal of Marine Systems, 88 (1), 74-81.

Torsvik, T.; Soomere, T.; Didenkulova, I., and Sheremet, A. 2015. Identification of ship wake structures by a timefrequency method. Journal of Fluid Mechanics, 765, 229251. 